\title{
A Comparison between Transcutaneous Bilirubin (TcB) and Total Serum Bilirubin (TSB) Measurements in Term Neonates
}

\author{
Pushpendra Kumar ${ }^{1}$ \\ ${ }^{1}$ Assistant Professor, Department of Paediatrics, Teerthankar Mahaveer Medical College, TMU, Moradabad, Uttar Pradesh, India.
}

\section{Abstract}

Background: Noninvasive transcutaneous bilirubin measurement is an simple quick, and painless, method for jaundice evaluation in newborns. But variable accuracy had been reported in different studies. The aim of the study was to find out the correlation and agreement between TcB and TSB measurements in neonates. Subjects and Methods: A descriptive cross-sectional study was performed on 200 full term (37 gestational weeks) neonates weighing more than $2.5 \mathrm{~kg}$.TcB was measured using a bilirubinometer three times on the forehead and mean levels were calculated. Then, during the successive 30 minutes blood samples were acquired and send off to the laboratory for determining the Total Serum Bilirubin (TSB) levels. Results: Out of 100 neonates, $62(62 \%)$ were males and $38(38 \%)$ were females, with a mean age of 5.6 \pm 4.1 days (ranging from: 1-20 days). Among all the neonates 99 neonates were on breastfed while 20 (20\%) neonates had a history of icter. There was a high specificity and sensitivity related to bilirubin levels between $12-15 \mathrm{mg} / \mathrm{dl}$. On the other hand sensitivity was higher and specificity was lower for bilirubin less than $12 \mathrm{mg} / \mathrm{dl}$. Conclusion: Results of the current study suggest that these is a highly significant correlation between total cutaneous bilirubin and serum bilirubin in term neonates. Moreover, total cutaneous bilirubin is painless and quick tool for the measurement of bilirubin and it would be helpful in following neonatal icter. However, total cutaneous bilirubin has a high sensitivity in detecting icter, it should not replace total serum bilirubin due to its relatively low specificity. That is why we strongly suggest measurement of total cutaneous bilirubin is essential with assessment of total serum bilirubin in high risk neonates.

Keywords: Neonatal Icter, Serum bilirubin, Transcutaneous bilirubin.

Corresponding Author: Dr. Pushpendra Kumar, Assistant Professor, Department of Paediatrics, Teerthankar Mahaveer Medical College, TMU, Moradabad, Uttar Pradesh, India.

Received: November 2018

Accepted: December 2018

\section{Introduction}

Neonatal hyperbilirubinemia is a common problem with incidence of around $60 \%$ in term babies and nearly 80 $100 \%$ during first week of life ${ }^{[1]}$ are among the complications induced by hyperbilirubinemia.the increased bilirubin level in blood may lead to complications like Transient encephalopathy and kernicterus, which also has long term morbidity in form of cerebral palsy. ${ }^{[2,3]}$

Measuring bilirubin levels is a vital phenomenon for better treatment of neonatal jaundice which is generally done by visual, cutaneous, and serum evaluations. ${ }^{[4]}$ Even though visual evaluation is easy and effortless, it has two most important shortcomings; it is dependent on the physicians experience with no precise and reliable criteria, and possible estimations in this method are based on the cephalocaudal trend of jaundice. In addition, the colour of skin and clothes as well as the lighting, affect the visual evaluation. ${ }^{[4-6]}$

Measurement of Total serum bilirubin (TSB) is also not an perfect technique of measurement because of frequent blood sampling it could have complications such as infection, anemia, pain, and stress. Additionally, this method is stressful, time consuming and pricey. ${ }^{[1]}$ In cases at a high risk of kernicterus such as day-one icter, hepatosplenomegaly, etc, TSB measurement, follow-up and hospitalization are essential. ${ }^{[7,8]}$

In recent decades, for reducing patients' stress, laboratory expenses, and the need for blood sampling noninvasive bilirubin measurements have been accessible and transcutaneous bilirubinometry $(\mathrm{TcB})$ is one of these noninvasive methods. ${ }^{[9]}$ Using light waves in $\mathrm{TcB}$, the bilirubinometer is pressed against the skin causing pallor, and bilirubin levels measured in different ways. ${ }^{[10,11]}$ Different results have been capitulated in studies comparing the correlation between TSB and TcB. A relatively high correlation between TSB and TcB has been found by Briscoe and colleagues ${ }^{[12]}$; whereas no clear relationship has been found by Janjindamai et al. between the results of the two measurements. ${ }^{[13]}$ Karon et al. illustrate that TcB is a sensitive but nonspecific technique for calculating the risk of neonatal icter. ${ }^{[14]}$

A comprehensive study has been presented by Schwartz et al. in 2011 on the different methods for the diagnosis and management of hyperbilirubinemia. ${ }^{[15]}$ In 2012, different researchers like Mantagou et al. ${ }^{[16]}$, Wainer et al. ${ }^{[17]}$, 
Bosschaart et al. ${ }^{[18]}$ and Sajjadian et al. in Iran ${ }^{[19]}$ deal with the bilirubin measurements especially in neonates.

In recent times several studies have been published about this topic due to importance of bilirubin measurement. ${ }^{[20-24]}$ In view of the importance of this issue and the contradiction between earlier studies about the accuracy of $\mathrm{TcB}$, we aimed to compare the relationship between $\mathrm{TcB}$ and $\mathrm{TSB}$ measurements in term neonates. In addition, we have also considered the sensitivity and specificity of TcB based on the age of the neonates and bilirubin levels.

\section{Subjects and Methods}

A descriptive cross-sectional study was performed on 200 full term (37 gestational weeks) neonates weighing more than $2.5 \mathrm{~kg}$ in Department of Paediatrics of a tertiary care centre. This study was conducted from September 2018 to November 2018. The parents of all newborns enrolled in the study gave verbal informed consent after the aim of the study was described to the parents.

Exclusion criteria: The neonates who had not formerly undergone phototherapy or blood transfusion. Premature neonates, those less than $2.5 \mathrm{~kg}$, or neonates suspected of septicemia, meningitis, and cholestasis were excluded from the study.

Neonates who seem icteric visually at the clinic were observed by a pediatric resident and if they had the inclusion criteria for the study, their bilirubin levels were measured three times on the forehead for avoiding any bias induced by the bilirubinometer. Cutaneous bilirubin was measured by a pediatric resident. The skin was lightened due to the pressure when the apparatus is put on the skin and then the bilirubin was measured by using light waves in different ways. The radiated light goes to sub-cutaneous layer through the skin and reflected. Based on the reflected wave specifications, the cutaneous bilirubin is calculated.

Within 30 minutes blood samples were obtained and the mean levels were documented and then sent to the laboratory for determining TSB.Blood samples were collected from brachial vein of neonates by the nurse of neonatal ward of the Hospital. TSB was measured using a bilirubinometer. The comparison of the two measurements obtained from the two methods were recorded .

Neonatal data were also collected including: age, sex, birth weight, current weight, height, onset of jaundice, birth order in the family, history of jaundice in the family, type of delivery, type of feeding, history of hospitalization, neonatal and maternal blood group, history of phototherapy, priority and distance of measurements in serum and skin bilirubin, history of blood transfusion in newborn, and maternal prenatal care.

\section{Statistical analysis:}

Data were analyzed using SPSS software, version 16. Independent t-test (to compare the quantitative variable in the two studied groups) and Pearson's correlation coefficient (to evaluate effective parameter on dependent variable) were used accordingly.

\section{Results}

Out of 100 neonates, $62(62 \%)$ were males and $38(38 \%)$ wcre femalcs, with a mean age of $5.6 \pm 4.1$ days (ranging from: 1-20 days). Among all the neonates 99 neonates were on breastfed while $20(20 \%)$ neonates had a history of icter. The mean weight of the neonates was $3010 \pm 356$ grams. Further, results of the current study revealed that majority of the neonates of the study were the first child (54\%) followed by the second child $12 \%$, third and next child $34 \%$ neonates. Most of the neonates (60\%) showed icteric on day 4 or more, while $27 \%$ on 2 to 3 days. $12 \%, 27.5 \%$, and $60.5 \%$ of the neonates became icteric on days 1, 2-3, and 4 or more of birth respectively [Table 1].

Table 1: Distribution of the neonates according to different variables.

\begin{tabular}{|c|c|c|}
\hline Variables & $\begin{array}{ll}\begin{array}{l}\text { Number } \\
\text { neonates }\end{array} & \text { of } \\
\end{array}$ & $\begin{array}{l}\text { Percentage of } \\
\text { neonates }\end{array}$ \\
\hline Male & 62 & $62 \%$ \\
\hline Females & 38 & $38 \%$ \\
\hline $\begin{array}{l}\text { Weight } \\
2500-3000 \mathrm{gm} \\
3001-3500 \mathrm{gm} \\
>3500 \mathrm{gm}\end{array}$ & $\begin{array}{l}60 \\
30 \\
10\end{array}$ & $\begin{array}{l}60 \% \\
30 \% \\
10 \% \\
\end{array}$ \\
\hline $\begin{array}{l}\text { History of icter } \\
\text { Yes } \\
\text { No }\end{array}$ & $\begin{array}{l}40 \\
60\end{array}$ & $\begin{array}{l}40 \% \\
60 \%\end{array}$ \\
\hline
\end{tabular}

There was an insignificant relation among serum and cutaneous bilirubin and family history of jaundice. There was an insignificant relation between hyperbilirubinemia and delivery type. Further, results of the current study showed there was no significant relationship between history of hospitalization and serum and cutaneous bilirubin. In addition, an insignificant relationship was recorded between nutrition and serum and cutaneous bilirubin.

Frequency of blood group distribution among neonates with hyperbilirubinemia showed that higher level of bilirubin was common among B blood group followed by A+ blood group. On the other hand results revealed that jaundice was most common in neonates with $\mathrm{O}+$ blood group mothers (40\%) followed by $\mathrm{A}+$ blood group mothers (32\%).

Results showed that mean serum bilirubin was $19.35 \pm 6.34$ $\mathrm{mg} / \mathrm{dl}$ while, mean cutaneous bilirubin level was $18.88 \pm 5.86$ $\mathrm{mg} / \mathrm{dl}$. There was significantly high correlation (0.9) between serum bilirubin and cutaneous bilirubin.

It is evident from fig 1 that there was a high specificity and sensitivity related to bilirubin levels between $12-15 \mathrm{mg} / \mathrm{dl}$. On the other hand sensitivity was higher and specificity was lower for bilirubin less than $12 \mathrm{mg} / \mathrm{dl}$. 




Figure 1: Specificity and sensitivity of cutaneous bilirubin levels in comparison of serum bilirubin levels.

Table 2 shows that the positive and negative predictive values of TcB were 93.9 and 69.2. (In this table bilirubin levels below 12 were considered as normal) Present study also calculated the sensitivity and specificity of Cutaneous Bilirubin levels with respect to age. The highest sensitivity and specificity of Cutaneous Bilirubin was recorded on day three after the birth of neonates. In general, the sensitivity and specificity of Cutaneous Bilirubin compared with Serum Bilirubin was $95.1 \%$ and $67.7 \%$, respectively.

Table 2: Frequency and percentage of Serum bilirubin versus cutaneous bilirubin.

\begin{tabular}{|c|c|c|c|c|}
\hline Variables & & $\begin{array}{c}\text { Serum } \\
\text { bilirubin }\end{array}$ & & Total \\
\hline \multirow{3}{*}{$\begin{array}{c}\text { Cutaneous } \\
\text { Bilirubin }\end{array}$} & Abnormal & $77(93.9 \%)$ & $5(6.1 \%)$ & $82(100 \%)$ \\
\cline { 2 - 5 } & Normal & $4(30.8 \%)$ & $9(6.2 \%)$ & $13(100 \%)$ \\
\hline \multirow{2}{*}{ Total } & & $81(85.3 \%)$ & $\begin{array}{c}4 \\
(14.7 \%)\end{array}$ & $95(100 \%)$ \\
\hline
\end{tabular}

\section{Discussion}

Results of the current study revealed a highly significant correlation between cutaneous bilirubin and serum bilirubin levels in neonates. These findings are consistent with the findings of the earlier studies of Bhutani VK et $\mathrm{al}^{[8]}$ as they recorded a high correlation $(\mathrm{r}=0.91)$ between cutaneous bilirubin and serum bilirubin levels in neonates over $2.5 \mathrm{~kg}$ in weight. Various other studies have been done to assess the correlation between both of these. ${ }^{[25-28]}$ Similarly, Sanpavant $\mathrm{S}$ et $\mathrm{al}^{[28]}$ observed significantly high correlation coefficient of 0.8 between cutaneous bilirubin and serum bilirubin in full term healthy neonates. Alike, Briscoe L et $\mathrm{al}^{[12]}$ showed a significant correlation coefficient of 0.76 for cutaneous bilirubin and serum bilirubin levels in neonates. Further, present study recorded a high specificity for bilirubin levels over $12 \mathrm{mg} / \mathrm{dl}$, especially for the bilirubin levels between 12-17 mg/dl. However, specificity was decreased while sensitivity was increased for the bilirubin less than $12 \mathrm{mg} / \mathrm{dl}$; which may lead to increase number of false positives. These findings are in agreement to the findings of previous study of Liete $\mathrm{MG}$ et $\mathrm{al}^{[29]}$ recorded a high correlation between serum bilirubin and cutaneous bilirubin for the neonates having lower than $14 \mathrm{mg} / \mathrm{dl}$.

Our study showed that sensitivity was higher and specificity was lower in neonates for bilirubin less than $12 \mathrm{mg} / \mathrm{dl}$. Moreover, present study recorded that during first three days specificity was lower and sensitivity was higher. This may lead to increase number of false positive cases. On the other hand from day three onwards specificity and sensitivity both were higher which in turn results in decrease number of false positive cases.

These findings are supported by the earlier study of Romangoli $\mathrm{C}$ et $\mathrm{al}^{[30]}$ as they recorded that specificity of bilirubin level was significantly increased after 60 hours of birth in comparison of before starting 60 hours after the birth of neonates. Similarly, Hemmati $F$ et $\mathrm{al}^{[31]}$ showed significantly increase in specificity after three days of neonates birth.

Present study recorded higher bilirubin on fifth to sixth days after the birth. Whereas, most of the neonates are discharged from the hospital 48 hours after birth. That is why, cutaneous bilirubin measurement might be an easy and quick technique for the follow up of neonates with or without jaundice.

The practical approach towards our findings is that observing the high sensitivity of total cutaneous bilirubin may predict neonatal icter. Nevertheless, we have accentuated in our study that cutaneous bilirubin should be measured in neonates with various haemolytic disorders or infections in which bilirubin level is found higher. Similar to our study Briscoe L et al ${ }^{[12]}$ emphasized on use of cutaneous bilirubin measurement for the neonates with higher bilirubin level besides it has a low accuracy compare to serum bilirubin estimation. In contrast to this Janjindamai et $\mathrm{al}^{[13]}$ suggested that cutaneous bilirubin is as accurate as serum bilirubin. However, few researchers did not recommended cutaneous bilirubin over serum bilirubin. ${ }^{[12,32]}$

We have not evaluated the effect of phototherapy in neonates with higher cutaneous bilirubin or higher serum bilirubin level. On the other hand Tan KL et al recorded a lower correlation coefficient in regions exposed to phototherapy compared with the control group in their study.

\section{Conclusion}

Results of the current study suggest that these is a highly significant correlation between total cutaneous bilirubin and serum bilirubin in term neonates. Moreover, total cutaneous bilirubin is painless and quick tool for the measurement of bilirubin and it would be helpful in following neonatal icter. However, total cutaneous bilirubin has a high sensitivity in 


\section{Kumar; Transcutaneaus Bilirulin (Jcß) and Jatal Serum Bilirulin (JSB) Measurements in Term Neanates}

detecting icter, it should not replace total serum bilirubin due to its relatively low specificity. That is why we strongly suggest measurement of total cutaneous bilirubin is essential with assessment of total serum bilirubin in high risk neonates.

\section{References}

1. Kliegman RM, Stanton BF, St. Geme JW, Schor NF, Behrman RE, Nelson Textbook of Pediatrics. ed.19. Philadelphia, PA: Flsevier/Saunders; 2011. p. 603-9.

2. Shapiro SM, Nakamura H. Bilirubin and the auditory system. J Perinatol 2001; 21(1):52-5.

3. Brodersen R, Stern L. Deposition of bilirubin acid in the central nervous system: a hypothesis for the development of kernicterus. Acta Paediatr Scand 1990; 79(1):12-19.

4. American Academy of Pediatrics, Subcommittee on Hyperbilirubinemia. Management of hyperbilirubinemia in the newborn infant 35 or more weeks of gestation. Pediatrics. 2004. 114(4):297-316.

5. Engle WD, Jackson GL, Sendelbach D, Manning D, Frawley WH Assessment of a Transcutaneous Device in the Evaluation of Neonatal Hyperbilirubinemia in a Primarily Hispanic Population. Pediatrics 2002; $110(11): 61-7$.

6. Bhutani VK, Johnson LH, Keren R. Diagnosis and management of hyperbilirubinemia in the term neonates: For a safer first week. Pediater clin North Am 2004; 51(4):843-61.

7. Seidman DS, Paz I, Stevenson DK, Laor A, Danon YL, Gale R. Neonatal hyperbilirubinemia and physical and cognitive performance at 17 years of age. Pediatrics $1991 ; 88(4): 828-33$.

8. Bhutani VK, Gourley GR, Adler S, Kreamer B, Dalin C, Johnson LH. Noninvasive measurement of total serum bilirubin in a multiracial predischarge newborn population to assess the risk of severe hyperbilirubinemia. Pediatrics 2000; 106(2):17-26.

9. Bertini G, Rubaltelli FF. Non-invasive bilirubinometry in neonatal jaundice. Semin Neonatol 2002; 7(2):129-33.

10. Rubaltelli FF, Gourley GR, Loskamp N, Modi N, Roth-Kleiner M, Sender A, Vert P. Transcutaneous bilirubin measurement: A multicenter evaluation of a new device. Pediatrics 2001; 107(6):126471.

11. Ebbesen F, Rasmussen LM, Wimberley PD. A new transcutaneous bilirubinometer, BiliCheck, used in the neonatal intensive care unit and the maternity ward. Acta Paediatr 2002; 91(2):203-11.

12. Briscoe L, Clark S, Yoxall C. Can transcutaneouse bilirubinometry reduce the need for blood tests in jaundiced full term babies? Arch Dis Child Fetal Neonatal Ed 2002; 86(3):190-2.

13. Janjindamai $W$, Tansantiwong $T$. Accuracy of transcutaneous bilirubinometer estimates using Bilicheck in Thai neonates. J Med Assoc Thai 2005; 88(2):187-90.

14. Karon BS, Teske A, Santrach PJ, Cook WJ. Evaluation of Bilicheck Noninvasive Bilirubin Analyzer for Prediction of Serum Bilirubin and Risk of Hyperbilirubinemia. Am J Clin Pathol 2008; 130(6):976-82.

15. Schwartz, HP, Haberman BE, Ruddy RM. Hyperbilirubinemia: current guidelines and emerging therapies. Pediatr Emerg Care 2011; 27(9):884-9.

16. Mantagou L, Fouzas S, Skylogianni E, Giannakopoulos I, Karatza A. Trends of Transcutaneous Bilirubin in Neonates Who Develop Significant Hyperbilirubinemia. Pediatrics 2012; 130(4):898-904.

17. Wainer S, Parmar SM, Allegro D, Rabi Y, Lyon ME. Impact of a transcutaneous bilirubinometry program on resource utilization and severe hyperbilirubinemia. Pediatrics 2012; 129(1):77-86.

18. Bosschaart N, Kok JH, Newsum AM, Mentink R, Leeuwen TG, Aalders MC. Limition and Opportunities of Transcutaneous Bilirubin Measurements. Pediatrics 2012; 129(4):689-94.

19. Sajjadian N, Shajari H, Saalehi Z, Esphahani F, Alizadeh Taheri P. Transcutaneous bilirubin measurement in preterm neonates. Acta Med Iran 2012; 50(11):765-70.

20. Kasiri KA, Nourbakhsh SMK, Khalili Boroujeni T, Khoshdel A. Correlation of transcutaneous and serum bilirubin levels in infants with neonatal jaundice hospitalized in Hajar Hospital in Shahrekord. Pejouhandeh 2013; 18(4):189-94.

21. Hemmati F, Kiyani Rad N. The Value of Bilicheck $®$ as a Screening Tool for Neonatal Jaundice in the South of Iran. Iran J Med Sci 2013; 38(2):122-8.

22. Jahangiri M, Sharif MR, Movahedian AH, Moravveji SA, Mohammadi-Ashiani A, Jazayeri H. Correlation between the reported transcutaneous bilirubin and serum bilirubin in icteric term neonates before and during photothetrapy. Feyz 2013; 17(1):54-60.

23. Nagar G, Vandermeer B, Campbell S, Kumar M. Reliability of Transcutaneous Bilirubin Devices in Preterm Infants: A Systematic Review. Pediatrics 2013; 132(5):71-81

24. Maisels MJ. Transcutaneous Bilirubin Measurement: Does It Work in the Real World? Pediatrics 2015; 135(2):364-366.

25. Ho HT, Ng TK, Tsui KC, Lo YC. Evaluation of a new transcutaneous bilirubinometer in Chinese newborns. Arch Dis Child Fetal Neonatal 2006; 91(6):434-8.

26. Lam TS, Tsui KL, Kam CW. Evaluation of a point of care transcutaneous bilirubinometer in Chinese neonates at an accident and emergency department. Hong Kong Med J 2008; 14(5):356-60.

27. Bhat YR, Rao A. Transcutaneous bilirubin in predicting hyperbilirubinemia in term neonates. Indian Journal of Pediatrics 2008; 75(2):119-23

28. Sanpavant S, Nuchprayoon I. Comparison of two transcutaneous bilirubinometers, Minolta Airshields Jaundice Meter JM103 and Spectrx Bilicheck I Thai neonates. Southeast Asian J Trop Med Public Health $2005 ; 36(6): 1533-7$.

29. Leite MG Granato Vde A, Facchini FP, Marba ST. Comparison of transcutaneous and plasma bilirubin measurement. J Pediatr 2007; 83(3):283-6.

30. Romangoli C, Catenazzi P, Barone G, Giordano L, Riccardo R, Zuppa AA, et al. BiliCheck vs JM-103 in identifying neonates not at risk of hyperbilirubinemia. Italian Journal of Pediatrics 2013; 39(46): 1-6.

31. Hemmati F, Kiyani Rad NA. The Value of Bilicheck as a Screening Tool for Neonatal Jaundice in the Sourth of Iran. Iran J Med Sci 2013; 38(2):122-8.

32. Boo NY, Ishak S. Prediction of severe hyperbilirubinemia using the Bilicheck transcutaneous bilirubinometer. J Pediatr Child Health 2007; 43(4):297-302.

Copyright: (C) the author(s), publisher. Asian Journal of Clinical Pediatrics and Neonatology is an Official Publication of "Society for Health Care \& Research Development". It is an open-access article distributed under the terms of the Creative Commons Attribution NonCommercial License, which permits unrestricted non-commercial use, distribution, and reproduction in any medium, provided the original work is properly cited.

How to cite this article: Kumar P. A Comparison between Transcutaneous Bilirubin (TcB) and Total Serum Bilirubin (TSB) Measurements in Term Neonates. Asian J. Clin. Pediatr. Neonatol.2018;6(4):13-16.

DOI: dx.doi.org/10.21276/ajcpn.2018.6.4.4

Source of Support: Nil, Conflict of Interest: None declared. 